\title{
Cascading climate change impacts and implications
}

\author{
Judy Lawrence $^{\mathrm{a}, *}$, Paula Blackett ${ }^{\mathrm{b}}$, Nicholas A. Cradock-Henry ${ }^{\mathrm{c}}$ \\ ${ }^{a}$ Climate Change Research Institute, Victoria University of Wellington, PO Box 600, Wellington 6140, New Zealand \\ ${ }^{\mathrm{b}}$ National Institute of Water and Atmospheric Research, PO Box 11115, Hillcrest, Hamilton 3251, New Zealand \\ ${ }^{\mathrm{c}}$ Manaaki Whenua - Landcare Research, Lincoln, New Zealand
}

\section{A R T I C L E I N F O}

\section{Keywords:}

Cascading impacts

Systems dynamics

Financial sector

Urban systems

Water services

\begin{abstract}
A B S T R A C T
Climate change is expected to have adverse impacts and implications for a range of human-environment systems. However, our understanding of the extent to which these impacts may propagate as cascades, compounding to form multiple impacts across sectors, is limited. Cascades result from interdependencies between systems and sub-systems of coupled natural and socio-economic systems in response to changes and feedback loops. The combined effects of interacting stressors may affect the ability of individuals, governments, and the private sector to adapt in time, before widespread damage occurs. We discuss the origins of cascading impacts thinking and present the results of an investigation of cascading impacts and implications in New Zealand. A participatory and collaborative approach was used through workshops and semi-structured interviews with sector informants, including engineers, local government staff, and financial risk managers and analysts from the financial services sectors. Qualitative data collection was combined with network and systems analysis to examine increased frequency of high-intensity rainfall events, sea-level rise and drought, across urban water infrastructure and the financial services, and the implications of cascading climate change impacts for governance. Results demonstrate that closer consideration of the combined effects of linked stressors can facilitate a better understanding of the scope and scale of climate change impacts. By using critical systems thinking in characterising and assessing how climate change impacts cascade across domains, we show the implications of cascades for their governance and reveal where climate change adaptation interventions might be focused. The research methods and insights into cascades provide a conceptual and practical basis for further development, which can inform the design of additional studies in other domains and jurisdictions.
\end{abstract}

\section{Introduction}

There is widespread evidence showing that climate change will result in adverse effects for much of the world, including higher temperatures, sea-level rise, increased heavy rainfall, and associated heat stress and inundation damage (Byers et al., 2018). Not all climate change impacts, will emerge in the same way or at the same time: some emerge abruptly, others slowly and are ongoing, and there can be multiple impacts which occur concurrently and in different combinations. The interactions between these impacts therefore will have spatial and temporal implications, propagating across different settings and contexts, and will require new methods of accounting for potential damages and to inform the design of appropriate responses.

Although the scope and scale of their effects are not yet well understood, empirical examples are beginning to suggest that climate

\footnotetext{
* Corresponding author.

E-mail addresses: judy.lawrence@vuw.ac.nz (J. Lawrence), paula.blackett@niwa.co.nz (P. Blackett), cradockhenryn@landcareresearch.co.nz (N.A. Cradock-Henry).
} 
change impacts and implications will propagate as cascades ${ }^{1}$ across physical and human systems (Hilly et al, 2018; IPCC, 2007; Lawrence et al., 2016; Rocha et al., 2018). For example, the combined effect of increased frequency of high-intensity storms, sea-level rise impacts, and more frequent storm tides, will have compounding impacts on the capacity of individuals, governments, and the private sector to adapt in time before loss and damages occur.

There is an urgent need, to better understand the extent, scope and implications of cascading changes (Challinor et al., 2018; Koks, 2018), highlighted by recent calls to recognise these emerging risks (Willner et al., 2018; World Economic Forum, 2018). With reference to Willner et al. (2018), Koks (2018) suggests that cascading effects of flood risk pose additional economic risks globally that can be of the same order of magnitude as asset damages within and outside the affected region; for example, that dependencies on infrastructure systems can be far away from the affected area. There may be no damage to those dependent on such infrastructure systems, so such cascading impacts would not be apparent using traditional risk assessments where the losses are to production. The World Economic Forum, in The Global Risks Report 2018, recognised that climate change is central to interdependencies between global risks, with extreme weather events, natural disasters, and failure of climate change mitigation and adaptation as three of the top five (World Economic Forum, 2018). These risks are described as highly interconnected because they cascade across many different domains. The Forum warns that systemic challenges have intensified over the previous year with signs of uncertainty, instability, and fragility. While it is necessary to prepare for sudden and dramatic disruptions, some events will slowly evolve but are, nevertheless, equally disruptive. For example, climate change exacerbates natural disasters and droughts, which affect food security and global insecurity (Challinor et al., 2018). Furthermore, some literature (Pescaroli et al., 2018) has analysed the implications of cascading crises across scales through vulnerability paths, creating secondary emergencies. Usefully, others provide a typology of inter-related risks (compound, interconnected, interacting and cascading risks) (Pescaroli and Alexander, 2018). However, we found little literature that has analysed cascades from slowly emerging and ongoing climate change impacts, in particular the implications for how we respond, our capacity to respond in time, how we organise ourselves to respond, and what the implications of our response options might be.

It is against this backdrop that the importance of understanding cascading impacts and implications of climate change emerges, not just at the global scale, but at the level of agency within affected systems, regions, and countries where key decisions are made becomes clear. Failing to adequately account for the complex ways in which climate change may result in cascading impacts across sectors and domains, can lead to blind spots in adaptation planning, with implications for adaptive capacity, and the ability to effectively mitigate risk through current governance regimes.

Our study seeks to gain insight into different types of climate change impacts: slowly emerging and ongoing ones, extremes, increased variability, surprises, compound impacts, and those that occur concurrently in time, including sea-level rise and rising groundwater tables. More specifically, the focus is on how impacts might cascade within, between, and across coupled domains, drawing on analysis of urban systems (including the underlying support systems that enable the provision of services and exchange for urban populations) and rural systems, and their links to water management (stormwater, wastewater, and water supply), and the financial services sector (insurance and banking).

The paper is organised as follows. First we review the literature on cascades to locate our study within the broader context of cascade thinking. We then discuss the methods used in this study. Next we present and discuss how cascades propagate across the three domains of interest, and their implications for governance. The paper concludes with some observations for policy and practice more generally and for further research.

\section{Cascading climate change impacts and implications}

The literature on cascading impacts and implications has been evolving in three parallel streams, with some evidence of interaction between them: socio-ecological resilience; disaster risk reduction and systems dynamics. Conceptually, all three have learned from one another, and share common elements drawn from ecology, social-ecological resilience, natural hazards research, systems and organisational theory. This is evidenced by a shared emphasis on 'linked-up' and systems thinking, and a focus on critical thresholds in natural, built, and human systems, and interactions and feedback loops between them.

A review of the literature shows the breadth of work relating to cascades, traversing ecosystems dynamics and their intersection with human-environment systems (Blenckner et al., 2015; Carey et al., 2017; Johnson et al., 2011), multiple hazard cascades, tipping points of harm, thresholds and surprise (Gill and Malamud, 2016; Walker et al., 2009), policy responses, and governance (Galaz et al., 2011; Reyer et al., 2012). Cascades have been defined and applied in a number of settings, including urban (da Silva et al., 2012; Tyler and Moench, 2012), infrastructure (Bollinger and Dijkema, 2016; Hu et al., 2016), and disaster risk reduction (Pescaroli and Alexander, 2016). The earliest conceptual work on cascades comes from studies of resilience, in which the focus is on linked socialecological systems (Walker et al., 2004). In these coupled human-natural (Carter et al., 2014) or socio-environmental systems (Turner et al., 2016), the cascades propagate as a result of significant changes to a key system variable. The loss of crucial ecosystem services for example, or a shift in land, water, or hazards management practices leading to widespread changes which, over time, result in the socio-ecological system changing state. The change in key variables results in a cascading effect that induces or accelerates the crossing of other thresholds in connected domains and sub-systems (Kinzig et al., 2006).

Cascades also present institutional and political challenges. For example, Galaz and colleagues focus on the governance of

\footnotetext{
${ }^{1}$ For the purposes of this paper we have adopted the following definitions. Cascading risks are those that develop due to a hazard and its impacts in situ to the systems affected, flowing out to other domains. Compound risks are those that develop due to more than one hazard interacting with another hazard on the human systems vulnerable to them.
} 
'cascading ecological crises' (CECs) (Galaz et al., 2011). Drawing on interdisciplinary studies of crises and change in complex and interacting social-ecological systems (Ostrom, 2007), and organizational theory and political decision-making studies (Boin et al., 2005; Smith and Elliott, 2006). Galaz et al. (2011) postulated three characteristics shared by CECs. The second of these has relevance to cascades from climate change impacts- those posing significant management challenges due to their cascading and recombining capacities, which require coordination of responses and decision-making by actors at multiple levels.

The 'cascade effect' is also a focus for disaster risk reduction - in which the direct impact of hazard events and/or crises generates a sequence of events in human sub-systems resulting in physical, social, or economic disruption (Pescaroli and Alexander, 2016). 'Cascading disasters' occur when cascading effects progress over time, generating unexpected secondary events of greater impact. An example is the failure of physical structures, and the social functions that depend on them, including critical infrastructure facilities; or where disaster reduction strategies are inadequate, such as evacuation procedures, land-use planning, and emergency management strategies (Pescaroli and Alexander, 2016).

Empirical examples of cascading disasters have largely focused on critical infrastructure and lifelines (such as telecommunications, electricity, and water) (Pescaroli and Alexander, 2016), hazard-network interactions (Gill and Malamud, 2016), and responses. Shimizu and Clark (2015), for example, discussed the difficulties in addressing suitable responses to earthquakes and hurricanes at a governance/ institutional level that focus on interconnected issues, such as public policies, infrastructure, economies, production and supply chains, and risks and uncertainties, which lead to unexpected consequences due to those interdependencies.

Other empirical studies have looked at cascading effects on terrestrial and marine systems or other physical ecosystems and human environment domains (Carey et al., 2017; Fountain et al., 2016; Latham et al., 2015). An example is how marine ecosystems change within and between species where climate change impacts exacerbate existing stressors (Niiranen et al., 2013). The complex, compounding, and cumulative nature of these impacts demonstrates how a better understanding of systems can illuminate potential effects of climate change. Further understanding can be gained through exploring system dynamics.

Systems dynamics seeks to better understand the interconnected nature of causality and effect (Sterman, 2000). It provides a conceptual framework and a set of tools that have been developed to help make these patterns of interconnectedness clearer. Understanding the structure of the various interacting factors can provide insight into key places to intervene or affect change. Systems dynamics has several unique properties - interconnections, feedback loops, and the ability to demonstrate and explore adaptive capacity, self-organisation, and emergence (Williams et al 2017). Systems dynamics literature highlights the critical elements of systems which are fundamental to understanding how cascades propagate and enable dependencies and interdependencies to be identified and thus provide a framing for considering cascading climate change impacts.

This short and non-inclusive review illustrates the diverse conceptual and theoretical insights that have been developed from the empirical evidence. There are concepts, heuristics and typologies being shared between fields. Moreover, there are few examples specifically focusing on the impacts or implications of climate change using systems methodologies, which include, impacts on energy constraints and policy (Ansell and Cayzer, 2018), water resources and water demand (Gastelum et al., 2018; Givens et al., 2018; Winz et al., 2009), food security (Guma et al., 2018), heat-related health impacts and early thinking on resilient architectural design (Weisz, 2018).

Challinor et al. (2018) use systems dynamics to advance a typology of systemic climate risks. Focusing on 'climatic risk transmission', they identify two potential roles for climate change within inter-related systems. First, climate change can be a trigger albeit with a long lead time - which results in risks propagating over long distances. Second, climate impacts can exacerbate real or perceived risks related to the availability of critical resources such as food or water (Challinor et al., 2018). In this case, where there is competition for resources, climate change may amplify perceptions of scarcity, increasing the likelihood of social impacts, for example, civil unrest in response to food insecurity. While this is a useful heuristic, much of the work on cascades using systems dynamics relies on numerical modelling and focuses primarily on biophysical or physical science subsystems. This leaves social systems largely unexamined in a systems dynamics framing, both by themselves, or connected to the biophysical and physical world.

Gaining insight into the scope of interconnectivity between internal and external stressors and sectors using critical systems thinking to describe cascading impacts and their implications, can support adaptation planning, help to avoid maladaptation, and reduce the incidence of negative cascades across the economy (Cash et al., 2006; Wilbanks and Kates, 2010). That is the focus of this paper.

\section{Methods}

To characterise and empirically document cascading and compounding impacts, in-depth qualitative research methods were used. Unlike conventional risk or impacts assessment which rely on numerical or probabilistic modelling to determine the expected impacts of climate change, we engaged directly with stakeholders and end users through a participatory and collaborative process intended to gain insight into stakeholders' understanding of affected systems (e.g. the cascading impacts and implications for urban water infrastructure). Connectivity between drivers of risk was further explored through the use of the interactive CIrcle Tool ${ }^{2}$ (Hounjet et al., 2016). Fig. 1 illustrates the process of data collection and analysis.

Based on our literature review, and drawing on earlier work on climate change impacts and implications at the national level (Lawrence et al., 2016), we developed a framework for characterising cascades. The framework systematises the interaction between cascades, who and how cascades affect the system of interest, where interdependencies and co-dependencies occur, and how far impacts and implications might extend across multiple geographic locations, scales, and sectors (MethodsX paper Cradock-Henry et al., 2020).

\footnotetext{
${ }^{2}$ CIrcle (Critical Infrastructures: Relations and Consequences for Life and Environment). Refer to https://www.deltares.nl/en/software/circlecritical-infrastructures-relations-and-consequences-for-life-and-environment-2/
} 


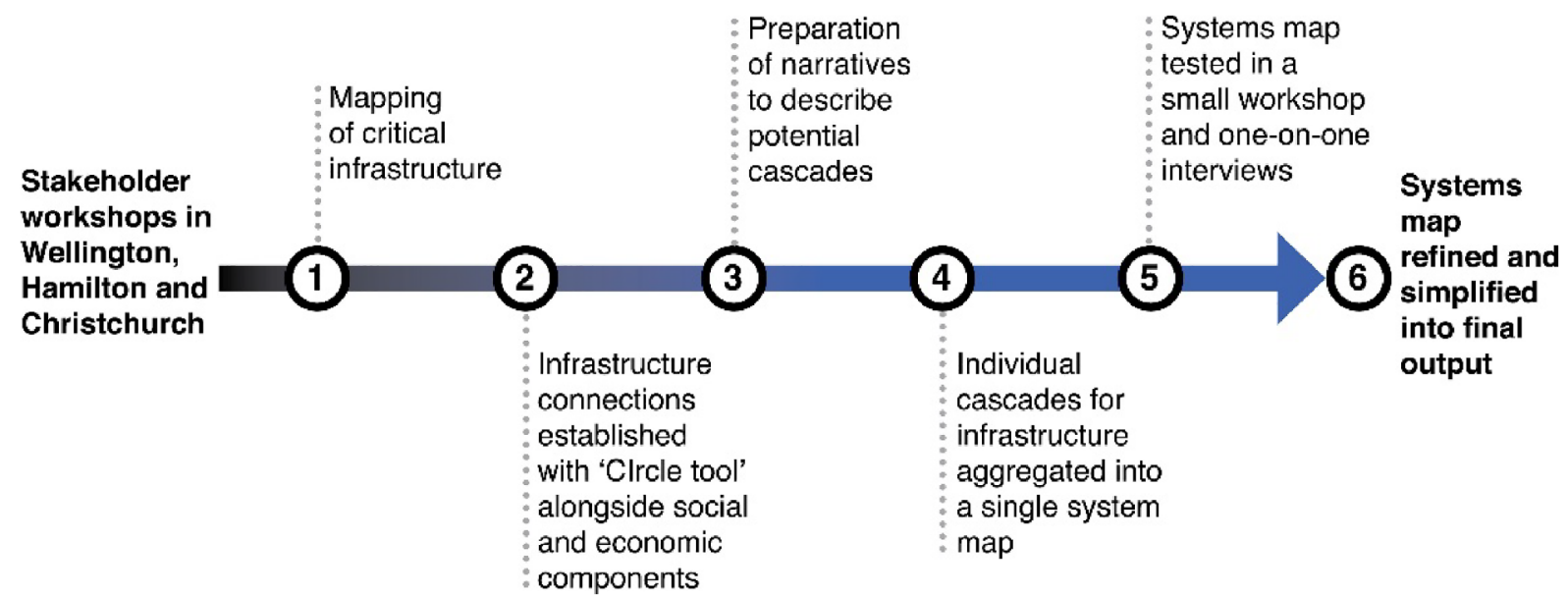

Fig. 1. The process of data collection and analysis.

An initial typology of impacts was developed to help distinguish the types of impacts that may cascade or compound, and to ensure a broad representation of them across the project. The five impacts are:

- Slowly emerging and ongoing - e.g., sea-level rise and associated rising groundwater tables;

- Widening climate variability - e.g., increased drought, flood, and coastal storm frequency and duration;

- Extremes - e.g., coastal storm surge, intense rainfall, and wind;

- Combined impacts - e.g., coastal and river flooding, and heavy rainfall and debris flow; and

- Surprises - e.g., as yet unknown impacts from atmospheric changes.

In order to gain insight into the complexity of cascades, a structured, stepwise and mixed methods approach was used. There were three phases to data collection and analysis: 1 Workshops with key stakeholders and informants; 2 Sense-making and gap analysis by the research team; and 3 Selective interviews of the original workshop participants to present and discuss our findings, and groundtruth the conclusions and recommendations in their daily practice.

Building on existing contacts and networks developed through previous climate change related research, three sites in New Zealand were identified where policy-makers and practitioners were already facing pressing issues flowing from the impacts of climate change. These sites presented different scales and types of systems, which reflected diversity, and provided an opportunity to compare contrasting areas. The sites were: Hamilton, a landlocked city adjacent to rural areas with flood risk, and conservation and tourism demands; Wellington, a capital city constrained by geography for access and egress, and surrounded by coasts; and Christchurch, a city set around low-lying estuaries and coast, recently lowered by earthquake subsidence, with significant flood and storm water challenges.

Cascading impacts as they relate to these particular domains of interest were chosen, first, because there is a gap in understanding in those domains (Lawrence et al., 2016), second, because these domains critically affect the ability of communities and financial systems to function and last, because cascading and compounding impacts have national implications. In short, they affect agency within a particular country setting. Examining cascading impacts at a country scale enabled us to place the cascades within the context of New Zealand's particular and unique governance arrangements, to derive lessons and insight for application in other jurisdictions.

Workshop participants $(n=39)$ were identified and recruited through purposive snowball sampling with agency contacts to obtain representatives from key local and national agencies with infrastructure management responsibilities or regulatory mandates. Participants came from different functional units within the agencies (urban, rural systems, and three waters infrastructure provision -stormwater, waste water and water supply) and were drawn from across diverse domains and geographical areas. Disciplines represented included planners, engineers, economists, geomorphologists and ecologists who work across asset management, flood risk management, integrated catchment management, strategic and statutory planning, transport planning, policy analysis, housing infrastructure, property management, and water planning and allocation. Half-day workshops were conducted at each location with minor refinements in process between the first workshop in Wellington and the subsequent workshops in Hamilton and Christchurch (Supplementary material Table 1-1).

The CIrcle tool was used to visually document the inter-dependencies between different types of infrastructure in real time. Linkages between components were added during workshop discussion, providing an additional opportunity for participants to iterate the system representation. Data was recorded using an audio recorder, along with CIrcle output files, and detailed notes taken by the authors. Permissions were obtained in advance, and all interviews were conducted in an ethical manner.

To supplement data from workshops, targeted interviews $(n=12)$ with key stakeholders were conducted. All those interviewed had participated in the workshop(s), or had direct experience or management responsibilities pertaining to the domains of interest. Interviewees were chosen for their willingness to participate in one on one interviews and for their insights from their domain. Interviews lasted up to one hour. Interviews were recorded and transcribed. Interview data were analysed using thematic content analysis (Braun and Clarke, 2006). Narratives for each domain were developed in order to identify critical nodes where impacts might 
potentially interact, and thus focus decision makers' attention. Systems thinking methodologies were used to derive insights from the stakeholder workshops and present in a more accessible and visually relevant format. The resulting systems maps illustrate the domain of interest (e.g. flood protection infrastructure) and its interactions and interconnections with other domains (Connolly and Blackett, 2018). Narratives and systems maps were pre-tested with a sub-group of key informants in a workshop to ensure it matched their experiences and reflected the preceding workshop, and then six targeted interviews were conducted with selected workshop participants and from the finance sector to test the veracity of the cascades. The systems map was used to guide interviewees through the conceptual and empirical framing of cascades, confirm system functionality, and address any gaps.

\section{Results and discussion}

Results from the analysis are presented below. Three domains are discussed: water, urban systems and infrastructure, and financial services. The following sub-sections discuss the different parts to the investigation: 1 systems maps are presented and described to identify the interconnected drivers of causes and effects underpinning the cascades; 2 narratives that were generated from the workshop findings; 3 examples from urban systems, and financial services domains and; 4 reflections on the governance implications of managing cascading risks.

The analysis shows the potential impacts and implications of cascades across diverse systems and domains. Connectivity between domains through physical linkages - such as built infrastructure, financial goods and services, and social systems dynamics - including community well-being and perceptions of risk - demonstrate the multiple ways in which the felt impacts of climate change will extend beyond the immediate direct impact making adaptation and any potential policy responses complex and requiring consideration of governance across domains and communities.

\subsection{Systems maps}

To illustrate how different types of climate change impacts (extreme events and slowly emerging and ongoing impacts) have similar interdependencies, feedback loops, and generate similar cascades across other domains, a systems map was developed, based on the results of the stakeholder workshops. The systems map (Fig. 2) illustrates the interconnections between the different subcomponents and shows interdependent cascades incorporating seven feedback loops across four sub-areas of the system

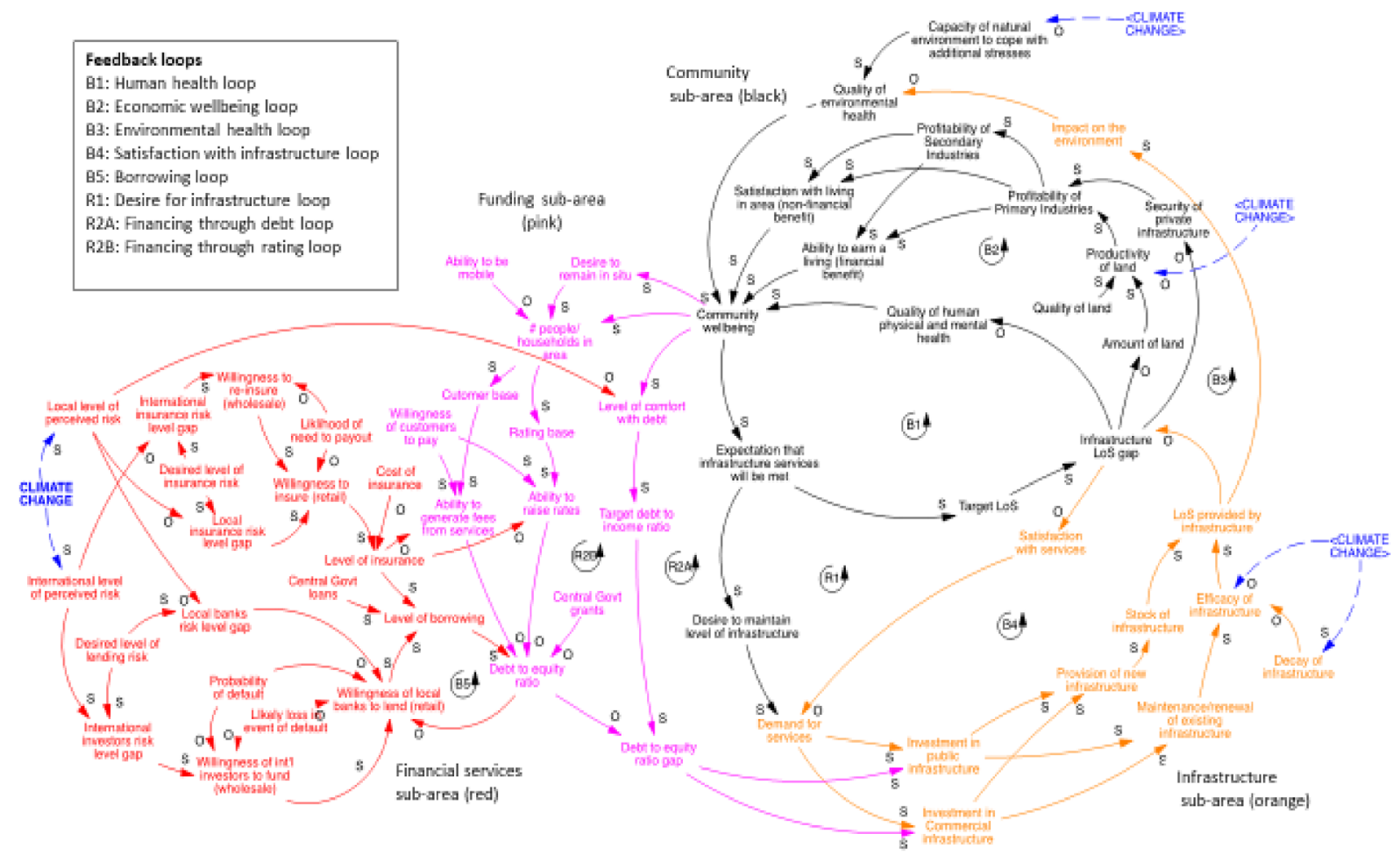

Fig. 2. Systems map showing cascading impacts across multiple domains. Key: Same ('s') arrows indicated that a change in the causal factor leads to a change in the same direction in the impacted factor. Conversely, opposite ('o') arrows indicate that any change in the direction of the causal factor will lead to a change in the opposite direction in the impacted factor. A reinforcing loop is when the direction of change in the first factor transfers around the loop influences back to that same factor in the same direction. These loops tend to compound over time either in a positive (virtuous) or negative (vicious) way. A balancing loop is when the direction of change in the first factor transfers around the loop influences back to that same factor in the opposite direction. These loops tend to cancel or 'balance' themselves out. 


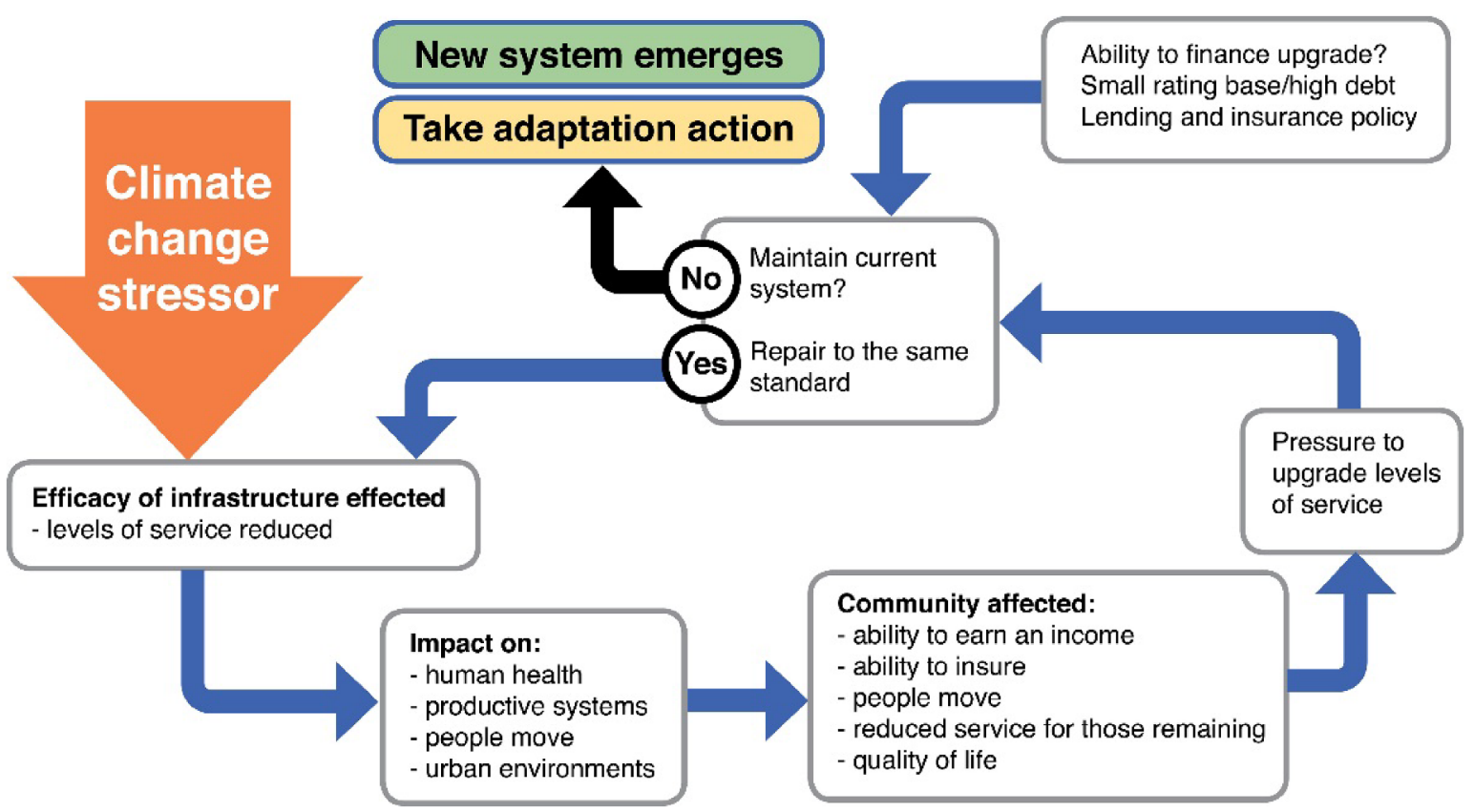

Fig. 3. Cascading systems loop applicable to wastewater systems, stop banks for flood protections, water supply, stormwater systems.

(infrastructure, community, and funding and financial services) (Lawrence et al., 2019). Importantly, the systems map shows how the cascades arise from a climate impact and move across space and organisations, affecting ecological, social, and economic domains. The cascades can move through a connected social-ecological system, combining or compounding, because of external policy decisions or concurrent impacts or events, and the different types of impacts can occur simultaneously at the same geographical location.

From the complex map (Fig. 2) a simple system loop was derived. This simplified map provided a basis for engaging stakeholders and to guide them through a step-wise exploration and discussion on cascades (Fig. 3).

Fig. 3 describes a cycle exposed for all the types of infra-structure explored for each of the types of climate change impact. Impacts may emerge continuously in the case of rising seas or groundwater tables, or suddenly due to an extreme weather event or a series of smaller weather events that increase in frequency. Fig. 3 presents a potentially vicious cycle of how cascades can emerge over time and space. Each loop begins with a climate change stressor that acts to reduce infrastructure efficacy. Consequentially, the impacts cascade with implications for human health, productive systems (farms, orchard), businesses and urban environments (property and public assets), affecting the resident communities. These effects may include loss of income, property, services, and effects on quality of life.

\subsection{Narratives of cascades and common implications}

In order to gain additional insight into cascades, narratives were derived from the workshop data to inform plausible stories or enrich existing empirical examples (Table 1). The narratives are used to further illustrate five examples of the viscous cycles discussed in Section 4.1, across critical infrastructure groups and type of climate change impact.

From these narratives, common implications across institutions, geographic locations and domains can be identified, including legacy effects of decisions, and increases in residual risk.

\subsubsection{Legacy effects of decisions}

If decisions do not account for changing climate impacts over time and the life-time of the infrastructure, the efficacy of infrastructure systems will be reduced with many flow-on implications. The financing of wastewater systems pipe maintenance is based on a design lifetime that is much shorter than when it was built. This is in part driven by pressures on decision makers to reduce rate rises (property taxes by local government for services) which results in tendering for repair work at lowest cost. This means that alternative more durable pipe technologies are often ruled out. There is currently limited ability to borrow more money to finance repairs, due to competing demands from other council functions and fiscal and legal risks associated with increasing council debt above statutory limits. This problem is compounded by corrosion across sewer networks, reducing life-time of pump station components that are not designed to withstand salt water, an increase in pump run hours because of increased flow volumes from stormwater and groundwater infiltration. By using systems analysis based on revealing cascading impacts, the implications for the policy assumptions for tendering and costing can be revealed which can reduce maintenance costs over time. 
Table 1

System narratives.

\begin{tabular}{|c|c|}
\hline System & Narrative \\
\hline $\begin{array}{l}\text { Wastewater systems: } \\
\text { (Sea level rise and rising groundwater tables } \\
\text { cascade) }\end{array}$ & $\begin{array}{l}\text { Saltwater intrusion into groundwater systems coupled with higher groundwater tables due to rising sea } \\
\text { levels will create multiple problems for wastewater systems: corrosion across sewer networks; reducing } \\
\text { life-time of pump station components that are not designed to withstand salt water; an increase in pump } \\
\text { run hours because of increased flow volumes from stormwater and groundwater infiltration. Waste-water } \\
\text { systems are more likely to fail as a result, particularly old systems already struggling with current loading } \\
\text { rates. Overflows, leaks or pump failure also present a health risk to local communities which if not fixed } \\
\text { will result in localised land and water contamination. More durable pipe technologies are available - but } \\
\text { are costly. Consequently at-risk components of the system are replaced with least cost solutions financed } \\
\text { by rate increases. However, these will have a shorter than anticipated lifespan and remain susceptible to } \\
\text { salt water corrosion. The result is a temporary return to the existing level of service which satisfies the } \\
\text { community, but the system remains highly vulnerable. }\end{array}$ \\
\hline Water supply systems (Drought cascade) & $\begin{array}{l}\text { Long dry periods cause ground movement (settling and cracking) affecting the integrity of pipe systems } \\
\text { responsible for supplying water. Older pipes are more brittle, and therefore vulnerable to damage and } \\
\text { leaking although new pipes can be affected. Resulting water loss needs urgent and immediate repair if } \\
\text { levels of service are to be maintained given likely dwindling water reserves. Planned maintenance/ } \\
\text { replacement schedules may have to be brought forward and accessing underground pipes in densely } \\
\text { populated areas is difficult and disruptive. Cracking can also allow sediment to enter the water supply } \\
\text { system potentially damaging pumping systems. Urgent pipe repairs require financial investment and time, } \\
\text { without which these water supply services could be compromised, affecting individuals and businesses. }\end{array}$ \\
\hline Stormwater systems (Heavy rainfall cascade) & $\begin{array}{l}\text { More frequent higher-intensity rainfall, compounded by infill housing, increases exposure by } \\
\text { overwhelming stormwater systems. This leads to localised flooding; inflow of stormwater to wastewater } \\
\text { systems; damage to property, roads, and stormwater networks; public health risks; sedimentation; and } \\
\text { potential death and injury. Older low-lying settlements with aging gravity stormwater systems and houses } \\
\text { built close to waterways or with floors close to the ground are particularly susceptible. Community } \\
\text { intolerance accelerates in response to repeat flooding, disruption, cost of evacuations, and the } \\
\text { ineffectiveness of agencies' responses. Current funding models to navigate local government debt limits } \\
\text { and the ability of communities to absorb rates increases become stressed, and homeowners who want to } \\
\text { move, face difficulty selling their property and feel stuck. The time lag required to establish new funding } \\
\text { arrangements for addressing the ongoing impacts creates general community stress and frustration. }\end{array}$ \\
\hline Stopbank breach (Extreme flood event cascade) & $\begin{array}{l}\text { An extreme rainfall event causes a stop bank breach as design standards are exceeded, flooding a } \\
\text { community and affecting power and water supply, waste water services, homes and businesses. Standing } \\
\text { water and flood damage affects people's ability to undertake social and economic activity and some leave } \\
\text { the community. Post event, pressure is put on local government to repair and upgrade the stop-bank to } \\
\text { prevent future flooding. Upgrade funding is approved (by council, rate payers and bank/insurer) for a } \\
\text { targeted rate increase and further borrowing. Residents feel safe again and continue with their lives. } \\
\text { However, the climate continues to change and subsequent flood events also overtop stop banks. The cycle } \\
\text { repeats, but this time access to lending and insurance from external sources is reduced as insurance and } \\
\text { banking sectors make decisions based on their perceptions of local flood risk. The stop bank is repaired but } \\
\text { not upgraded and the community has to adjust to greater residual risk. }\end{array}$ \\
\hline Power/Gas/ Internet (Storm event cascade) & $\begin{array}{l}\text { Currently, critical infrastructure and lifelines (e.g. telecommunications, electricity) are restored as quickly } \\
\text { as possible following a storm event. While utility companies manage risk in a proactive way, (such as } \\
\text { building redundancy and resilience into networks to better cope with storm-event outages), these } \\
\text { proactive actions are largely based on current climate conditions. The added impact of storm events (wind, } \\
\text { snow, flooding, and storm tides on top of sea-level rise) on utilities' service performance measures will } \\
\text { challenge current rating bases and borrowing limits. New ways of monitoring change using signals and } \\
\text { triggers for decisions ahead of damage thresholds, will be required, along with new funding methods that } \\
\text { anticipate the scale of the cascading impacts. }\end{array}$ \\
\hline
\end{tabular}

\subsubsection{Increase in residual risk}

Living with residual risk and reduced levels of service could become a reality for some locations. For example, use of stopbanks (levees) for flood risk management always has residual risk remaining which is often not recognised by communities without experience of large floods and their impacts (Ludy and Kondolf, 2012). Stopbanks are perceived as physical protection and are visible. Most of the time they stop flood damage. However, they have the effect of instilling a false sense of security in those 'protected' by them, witnessed by the assets and people continuing to build immediately behind them. This increases exposure to risk, and the damage that follows when bigger-than-design flows are eventually exceeded. Understanding the implications of cascading impacts of climate change where changes in the frequency of damaging pluvial events occur in protected river systems, can contribute to longterm resilience of communities in such areas. Long-term maintenance, monitoring and re-setting of risk design will be challenged by funding availability through rates and increasing costs as the climate changes.

\subsection{Domain examples}

\subsubsection{Urban systems and infrastructure}

Urban systems, including the underlying support systems for the provision of services and exchange and their dependent populations, will be affected by changes in climate, some of which may occur concurrently (Fig. 4). 


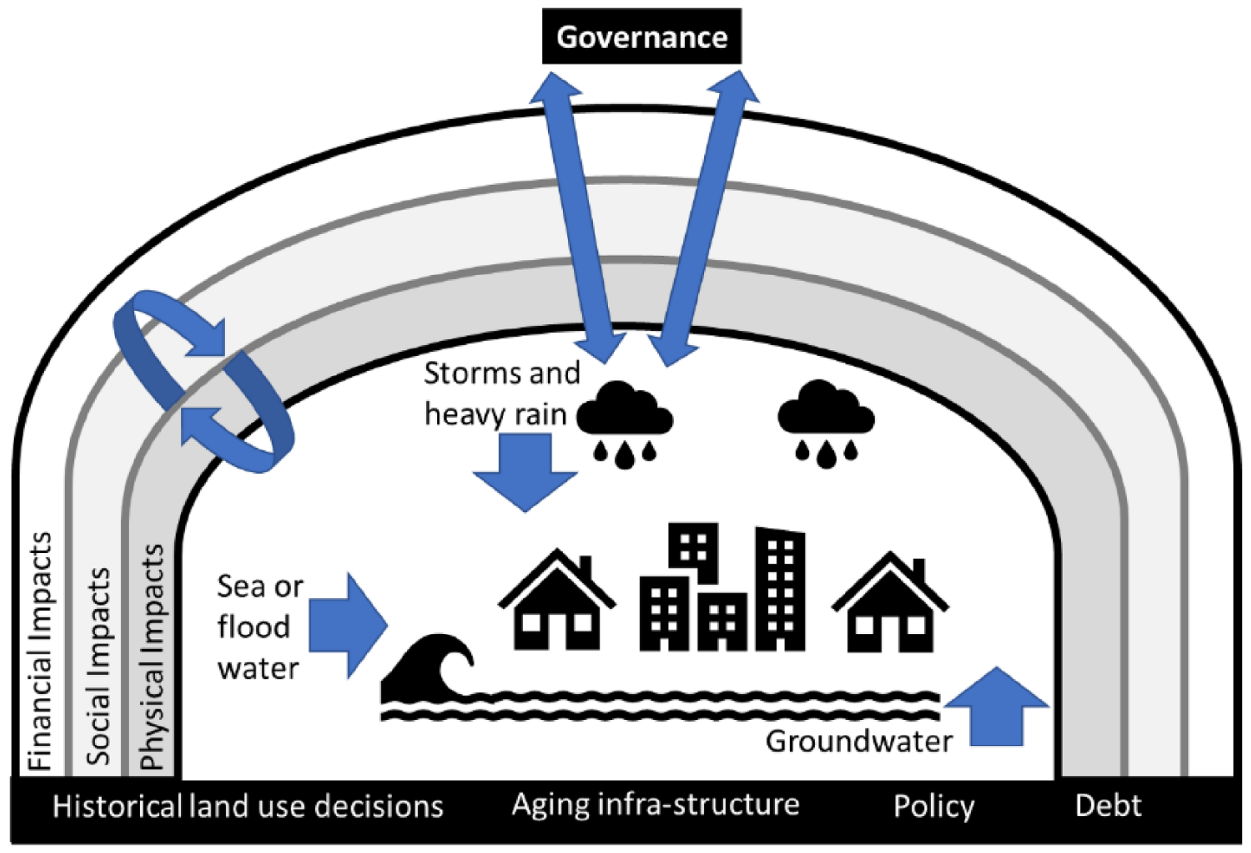

\section{Urban Systems}

Fig. 4. Multiple concurrent impacts of climate change on an urban system drawn from the workshops and interviews.

Urban systems and environments typically evolve over time, frequently in a piece-meal manner, under different planning rules, preferences for materials and technologies and prevailing policy assumptions. The resulting impacts from climate change and the implications experienced will depend on geographic location, the evolution of the community and associated infrastructure within the landscape, the prevailing growth pressures, levels of debt and the social/cultural and economic composition of the community. Such factors may constrain or enable urban systems to address cascading impacts and their implications for infrastructure and community cohesion. Fig. 4 shows the interrelationship and dependencies between the physical, social/cultural and financial impacts and with governance and the factors that predispose a community to risk.

It is almost certain that urban systems will experience a decline in services if several climate change impacts occur simultaneously (see Fig. 4). For example, rising seas and groundwater levels combined with increased flooding from heavy rainfall events, will challenge New Zealand's predominantly gravity-based stormwater systems. Stormwater drainage will be prolonged due to higher volumes and lower freeboard levels. Older homes with poor heating and ventilation will be most affected by standing water, exacerbating adverse health impacts for residents from damp and mould (refer to Fig. 2, B1-health). Concurrently, standing water may affect transportation networks, limiting the mobility of affected residents and business owners. Impacts on mobility will have a flow on effects for community functionality and ability to earn an income. Residents of older, poorly ventilated homes may already be vulnerable due to social or economic marginalisation (Cupples et al., 2007). Furthermore, households may have limited options to cope with the combined effects of an increased risk of respiratory illness and limits to their mobility other than to raise floor levels, waterproof buildings or relocate away from the hazard. Further cascades will occur if wastewater systems, water supply and electricity supply are similarly compromised. This example demonstrates the critical dependency between urban development and the infrastructure servicing urban systems.

As individuals, groups and businesses experience cascading climate impacts within their town or city, they are likely to be faced with a binary decision: stay or move. In staying, communities must either tolerate reduced levels of services and the associated effects (Fig. 5) or exert pressure on decision-makers to restore previous levels of service, seek new services or adaptation options. The ability to adapt, will depend on a number of factors, such as the availability of viable options, access to financial resources and power and opportunity to influence decision-makers. For many, their inability to relocate or strong attachment to place, may mean they accept emerging conditions and live with the residual risk. Over time, the areas most affected by climate change impacts could either be abandoned or populated by those with limited means, or by those willing to live with evolving risks. Elsewhere, there are hard limits to habitability. At coastal margins for example, where for those who move elsewhere, a tolerance threshold will have been exceeded or they possess the desire, financial means and opportunity to relocate. This may result in financial loss, depending on when the relocation occurred, or loss of connection to community and place.

\subsubsection{Financial services domain}

Financial services and governance domains play a critical role in determining whether or not adaptation to impending impacts and implications in urban systems can be realised. Funding availability and governance arrangements that establish the operating 


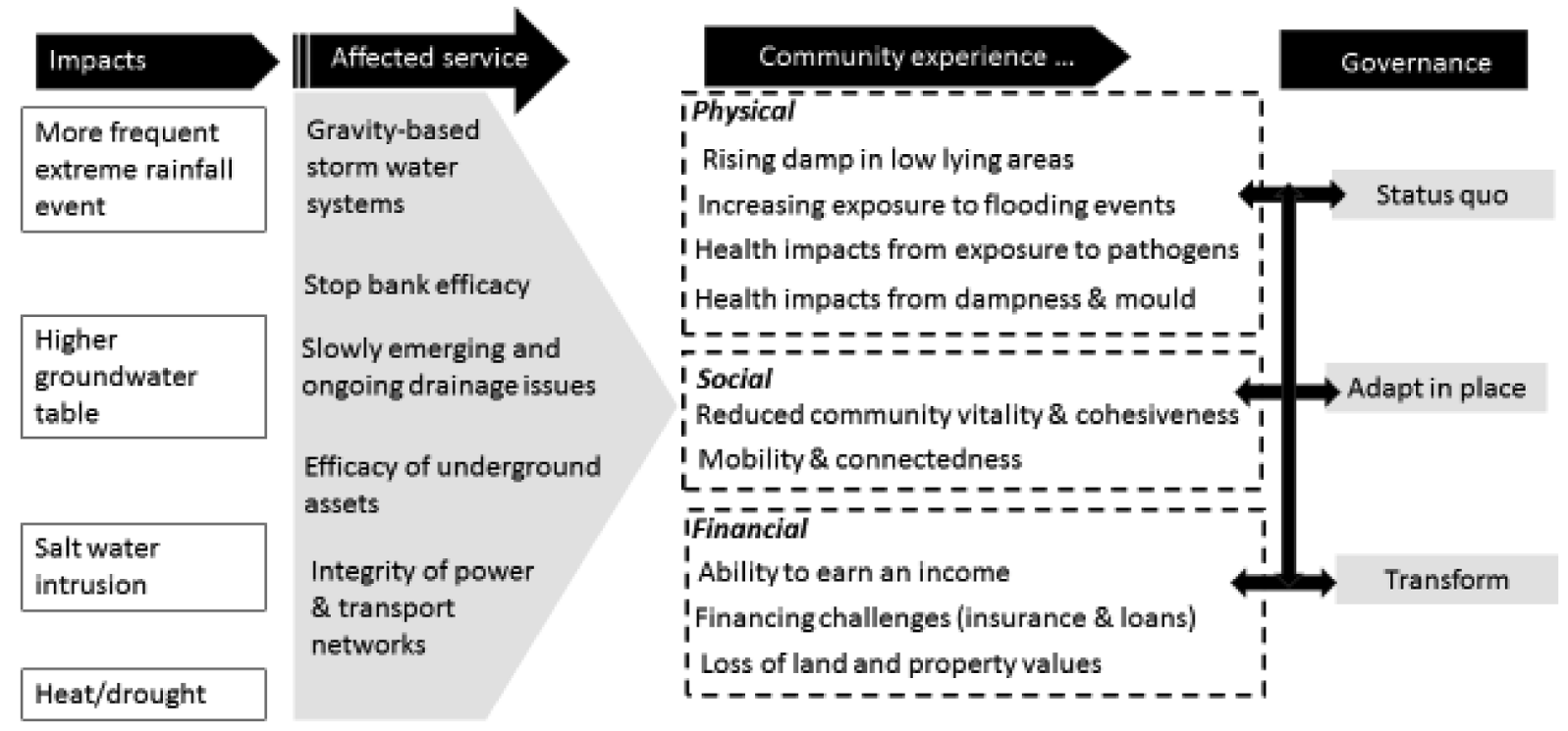

Fig. 5. Flow-on effects of climate change impacts in an urban system.

rules for adaptation decisions to be made, will have significant implications for businesses, individuals, and families, which in turn flow to central and local government funding of infrastructure maintenance, upgrades, or adaptation and transformational options, such as managed retreat from the coast.

Results from workshops and interviews highlight differences between insurance and banking sectors, and governance. The insurance industry has acknowledged the risk climate change presents to residential housing, and the link between insurance and borrowing, but believe they are flexible and able to respond to changing risks as they emerge (Table 2).

Similarly, participants from the banking sector acknowledge the possible impacts of climate change on their core business, and likely effects on the value of some assets, but are less clear how they might respond. Results from the Governance themes, are more complex and diverse, characterised by diffuse responsibilities, short-term political cycles and public perceptions and values.

Across these three domains, a number of dependencies can be identified. As noted above, the "relationship of availability of insurance and availability of borrowing is a hard on/off switch... insurance can be out within one year, but banks are stuck in it for 30 years and local government [and the State] for even longer" [Banking representative]. The quote illustrates the vicious cycle that may emerge

Table 2

Key issues: insurance and banking.

Insurance sector Acknowledge risk

Flexibility to respond to risk

Insurance and borrowing are binary

Increasing mortgage risk exposure

Sea-level rise will reduce and even eliminate asset value
Insurance in New Zealand is exclusively a risk transfer mechanism. Recent risk-based pricing adjustments in climate- and sea-level rise exposed areas is an acknowledgement of growing risk. The industry body (Insurance Council of New Zealand) has actively advanced the need for anticipatory planning and limits on insurance as a mechanism adaptation.

Many climate change impacts are least foreseeable even if timing and magnitude is uncertain in the future. Insurers have flexibility to respond to changing risk because they can adjust contracts with customers annually. "We don't insure certainties but only risks", said one insurer, the implication being, known hazard risks will increasingly be excluded from insurance cover. There two flow-on effects of climate change impacts with respect to mortgages: the customer's ability to service the debt, and the value of the security. Which one takes precedence depends on the individual circumstances of the customer. Customers either pay higher deductibles to reduce increased premiums if they can afford to, or they do not hold cover-locking them into staying put, abandoning their assets and moving, or becoming unable to afford to move and becoming dependent on the State. For commercial properties, the impact of the price signal can be more dramatic, depending on the relationship between the insurance costs and net income. The value of commercial property is derived from the income that can be generated from it. The cascading impacts are a transfer of risk to the individual or company, the taxpayer, and the ratepayer. There are further cascades to the State and local government if people cannot afford to adjust and require social support.

Exposure to changing and cascading climate change impacts is increasingly recognised. Exposure is especially contingent upon the insurance sector withdrawing from climate exposed locations or increasing premiums. Importantly, the banking sector acknowledges that insurance sector responses could initiate a sudden cascading issue which they will have little control over. Exposure to hazard risk, including compounding risk (e.g., coastal and river flooding, drought, wind, and intense rainfall events) in coastal regions will affect asset value. While the timing of decreases are unknown, regional differences can be identified on the basis of exposure. 
as a result of the interaction between insurance and property values. If homeowners are unable to insure their residence, property values will be depressed; if borrowing is reduced for business start-ups, this will impact on economic activity; and a vicious cycle ensues.

Policy responses by local government and national government also have the potential to create vicious cycles that lock-in assets and people in areas that will increasingly become affected by climate change impacts. For example, the insurance sector highlighted the interplay between council decisions to continue to consent buildings and subdivisions in at risk areas, and the sector's willingness to insure. If insurers become unwilling to provide cover, assets may be stranded with costs accruing to local and national government. The banking sector suggested that a change to the insurance business model could make a clearer link between insurance and planning to avoid further damages, with a funding regime to support this.

A durable national-level government funding model for addressing climate change impacts in a more anticipatory manner has been suggested (Boston \& Lawrence, 2018) that could be designed as a cost sharing arrangement between national, local governments and private beneficiaries of adaptation actions.

\subsection{Addressing cascading impacts: Implications for urban systems and financial services}

The narratives and sector responses suggest that anticipating the risk could help cushion the policy responses to cascading impacts. For example, adjusting to different classes of risk within the financial services sector (especially banking) takes time. Financial services are proscribed by stable regulations. However, panic behaviours by customers in response to risk-based signals, can occur very quickly and affect people's lives and asset values. In such circumstances, the risk is often transferred to the state or to people least able to aviod the consequences.

Different types of climate change risk will propagate different cascading impacts. For example, sea level rise is a certain risk and foreseeable. There are greater uncertainties for high-intensity storm events, drought, wind, and wildfire, which all exhibit great variability in time and space, but their consequences are foreseeable out to mid-century. Also different groups within society have different adaptive capacities to the impacts of climate change-for example, those in the rural sector have long adjusted to changes in climate within current variability, but may be challenged by the shift in variability ranges, depending on debt-to-income ratios. Others, like home owners, may have fewer options as the sea advances and extreme events become more frequent. Nevertheless, insurance signals before and after climate events can act as early warning of the need for individual and collective policy adjustments to be made.

Councils' willingness to withdraw services or not maintain protection levels as the risk increases, are levers available to councils within what is legally possible (Laing, 2018), and may become increasingly necessary to signal risk to communities, although not without equity issues. If councils signal where development can be located safely, this will incentivise development by increasing the confidence to invest, using available investment capital and new funding instruments to manage the investment. However, the insurance sector expressed concern that many councils have poor information on the state of their current assets, which means that risk assessment by the industry for insurance and lending purposes and for investment, is hampered. If risk-based planning tools and measures were to be used more widely by local government and their effect monitored by the Office of the Auditor-General routinely across the local government sector and reported to Parliament, the financial sector would have more confidence, which also may result in greater certainty for householders and the State. The insurance sector can walk away, but Government cannot. The implications for the funding of cascading climate change impacts through the current reactive strategies using the post hoc national EQC Fund or ad hoc funding by the State, will increase. How the State responds to this could have significant flow-on to individuals, the taxpayer, the local ratepayer, and for the financial sector. Consideration of who and how people pay is needed to avoid ongoing inequitable distribution of costs as climate change advances.

Building greater knowledge of the actual and potential cascading nature of climate change impacts is essential for building community and sector confidence for transitions to less-exposed locations, for transformational change in policy settings, and for supporting investment in adaptive options. Planning alongside effective community engagement is key for building a transition. Furthermore, understanding the flow-on consequences of the direct and indirect impacts and decisions about them, can inform interconnected management of cascading impacts in the context of national responses to disaster risk reduction under the Sendai Framework and climate change adaptation under the Paris Agreement.

\subsection{Addressing cascading impacts: Governance implications}

There were a number of inter-related governance issues that emerged from this research (Table 3).

These governance issues are discussed in turn due to their criticality for addressing cascading impacts.

\subsubsection{Ability of institutional arrangements to address cascading impacts}

Our research findings have highlighted practices by national and local government that have failed to anticipate the consequences of cascading impacts from climate change. Evidence of this can be seen over the last five years. For example, there has been one major stopbank failure in an urban area (Edgecumbe); many seawall breaches or over-toppings (e.g. Island Bay; West Coast, S Island); homes, roads and underground infrastructure regularly inundated by the sea (Mission Bay, Auckland; Granity, Hector, and Ngakawau-West Coast S Island); continued land subsidence from legacy drainage schemes making flood control during extreme rainfall events increasingly difficult to manage (Hauraki and Rangitaiki Plains); loss of valued natural habitat to erosion and inundation (Hauraki); loss of agricultural production from drought conditions, wind, and snow storms (North Canterbury and Central 
Table 3

Key issues: governance.

$\begin{array}{ll}\text { Governance } & \text { Short-term decision cycles } \\ & \text { Inadequate funding mechanisms } \\ & \text { Legal liability for not addressing hazard risks }\end{array}$

Visible damage from repeated and more frequent weather events and tide- and storm-related coastal flooding

Mixed messages make it harder in the short-term to reduce and avoid further risk exposure

Lack of interconnected institutional arrangements and organisations
Short-term political cycles and fragmented governance and decision frameworks are critical issues that combine to make addressing cascading impacts, difficult. Inadequate funding mechanisms to address climate change impacts as they cascade across many domains.

Legal liability for failing to address hazard risk is receiving heightened attention. This may accelerate the shift away from fears of litigation currently faced by councils when considering adaptation actions that affect the use of private property.

Visible damage from extreme events is increasingly motivating longer-term strategic planning that could address cascading impacts. For example, some councils are developing funding models for coastal hazard risk management (Hawke's Bay); multi-hazard assessments or 100- year strategies (Christchurch and Hawke's Bay). Elsewhere, strategies are shifting development away from the coast towards higher ground (Tasman District). Auckland City has embedded planning rules that reflect future sea-level rise scenarios over at least 100-years When special purpose legislation for housing and urban development are silent about natural hazards and climate change impacts for example, it may inadvertently encourage further development in low-lying coastal areas and floodplains which transfer new damage legacies and costs to future generations and to the taxpayer.

Lack of interconnected institutional arrangements and organisations that can work together on strategies for addressing cascading impacts, serve to highlight conflicting resource decisions in a context where the available funding and insurance are decreasing relative to the scale of the problem.

South Island), and damage to urban storm water systems (Wellington); and groundwater and flooding impacts on low-lying urban areas, especially where earthquakes have exacerbated these effects (Christchurch).

In response to advancing and foreseeable risks, insurance companies are now undertaking more granular risk rating which could result in premium increases or withdrawal from some areas for some classes of risk (Storey and Noy, 2017) e.g. where there has been repeat coastal, pluvial and fluvial flooding and for sea-level rise impacts. The consequence are likely to differentially affect vulnerable people, who are less able to pay and thus do not insure. This raises the potential that the risk is transferred increasingly to the Government (taxpayer) through ad hoc funding support to communities such as, the existing flood and drought relief schemes, placing them under greater pressure. Furthermore, Councils continue to grant consents in low-lying coastal and flood prone areas, underutilising available planning tools (CCATWG, 2017). Disconnected institutional arrangements and embedded reactive 'management' of hazard risk have created an institutional inertia that has proven difficult to shift (Lawrence, 2016).

\subsubsection{Planning and design life of assets}

Contemporary land use and infrastructure decisions that do not consider the effects of cascading impacts of climate change, set in motion expectations of ongoing 'protection'. Closer consideration to design-life of land uses and assets in a changing context will need to address some critical risks - such as ongoing sea-level rise which will be permanent and irreversible over many centuries, but which may not become fully visible for several decades. Similarly, the increased frequency of drought will have implications for landuse, and the need to avoid lock-in or path-dependency through over-capitalisation. For example, the sustainability of current water augmentation methods may be questioned as competition with urban water demand increases. More frequent rainfall events raises significant implications for the design of cities. For example, can our planning systems facilitate a shift from gravity stormwater systems, wastewater and flood management systems, to more yielding systems like 'sponge cities' or 'water-sensitive cities' that are gaining currency in the major cities of the world (Zevenbergen et al., 2018)?

\subsubsection{Managing community expectations of future levels of service}

Providing local government services under a changing climate will become increasingly fraught in climate exposed locations. Local government capacity to continue current levels of service under declining rating bases in the many small communities, will create cascading impacts on the viability of some of those communities. Sustaining the affordability of the current levels of service will be increasingly challenging for public agencies. For example, how performance measures of level of service (LoS) are expressed going forward, becomes a significant issue as current flood frequency changes, reaching thresholds for communities' coping capacity of the many cascading impacts. How councils respond to these challenges will be pivotal to their being able to fund the services. As a major period of infrastructure renewal in New Zealand coincides with ongoing increased risk from climate change impacts and increases in development exposure, a drop in level of service is inevitable, unless other forms of funding (beyond property taxes) can be accessed. New decision making frameworks, governance performance and decision making approaches are therefore, a part of the adaptation enablers going forward. Innovations in service design and planning are also part of the policy mix, to reduce the current legacy effects and to avoid creating new ones.

\subsubsection{Addressing uncertainty and changing risk profiles}

Currently, the practice of considering uncertainty and changing risk profiles associated with cascading climate change impacts, is 
under-developed. While new approaches are emerging (Lawrence et al., 2018), the capability deficit will take time to grow. Shifting away from the endemic predict-and-act and reactive mode for managing risk, will enable climate change impacts to be addressed more effectively, especially those that cascade across domains in time and space. Stress testing a range of options for short-term actions and for the long-term, against a range of future climate and societal scenarios, can provide better assurance to decision makers that they have built-in flexibility to change in synch, as the limits of current approaches are reached and flexibility in systems enables dependencies and lock-in of investment to be avoided. There are limits to building back in locations where there is increasing exposure to cascading impacts. Building-back-better, or somewhere else, creating redundancy in system design, connecting decisions taken today with their future functionality under worsening conditions, will help reduce large transfers of risk across communities and help to avoid stranded assets-the ensuring benefits can flow to future generations.

\subsubsection{Community engagement}

Communities are demanding engagement around the obvious impacts of climate change, not the least because decisions taken by responsible agencies will result in winners and losers amongst current and future generations with diverse interests (Barnett et al., 2014).

Collaborative planning models can engage the public in long-term thinking and planning that connects the different domains of interest to which impacts of climate change cascade. Such approaches are beginning to emerge. This has the potential to shift reactive decision making to more anticipatory modes. "We seem to spend a lot of time trying to solve the problem once the problem has occurred, which is one of the biggest follies. We are not very proactive" and "they [councils] make decisions on what the public want and you don't get the best outcome" [council officer]

\subsubsection{Funding and legal liability}

Urban domains demonstrate the large costs that come with inattention to cascading impacts across the different types of impacts. For example, most local government assets are underground. The value of the three waters infrastructure in New Zealand has been estimated at NZ\$44 Billion by Local Government New Zealand (Local Government New Zealand, 2015). The replacement value of infrastructure exposed to sea level rise alone is estimated at NZ\$8 Billion (Local Government New Zealand, 2019). This needs to be seen alongside the potential costs of cascading climate change impacts, such as those described in this paper; the secondary and tertiary impacts on health, social services, wellbeing, and to the many domains to which the cascades flow (Fig. 2). A durable national-level government funding model for addressing climate change impacts in a more anticipatory manner has been suggested (Boston and Lawrence, 2018) that could be designed as a cost sharing arrangement between national, local governments and private beneficiaries of adaptation actions.

\subsubsection{Political leadership}

Cascading climate change impacts also have significance for political leadership between levels of government and across parties in Parliament. One workshop attendee described recent attention to a wider examination of adaptation and mitigation as " $a$ shift - we can no longer rely on crises as a driver of change" (CCATWG, 2017, 2018; PCE., 2015). Cross-governance level responses have been elusive to date, although at a local level some councils are increasingly moving in that direction, for example, in Hawkes bay around coastal hazards and freshwater management leveraged by national level policy instruments ${ }^{3}$. National leadership is also emerging as the Government's climate change policy programme starts to be rolled out in response to its commitment to the Paris Agreement relating to both adaptation and mitigation through the Climate Change Response (Zero Carbon) Amendment Bill and as it implements the governance recommendations of the Climate Change Adaptation Technical Working Group (CCATWG 2018).

\section{Conclusions}

Through examination of a how climate changes lead to cascading impacts, we have revealed the far-reaching effects of climate change impacts that are amplified and generated through feedbacks and virtuous and vicious cycles. By constructing narratives and understanding dependencies using network and systems tools with practitioners, we have shown that siloed and linear consideration of impacts will conceal flow-on and feedback loops that can lead to responses that are not fit for purpose. By considering cascading impact trajectories and a full suite of impacts that impinge on the robustness of decisions, maladaptive responses can be minimised.

Cascades thinking has the potential to help bridge the gap between disaster risk reduction and climate change adaptation, because it enables the full implications of the initial stressor to be made transparent in space and time. It also enables the full human systems exposure and its change to be considered as climate change impacts intensify, enabling more transformative system-based responses to emerge. Such thinking has potential to provide a more nuanced framework for assessing interconnected and interdependent risks globally, as highlighted by the World Economic Forum and the UN DRR Global Assessments on Disaster Risk Reduction, to inform responses to the Sendai Framework for Diasater Risk Reduction and the Paris Agreement for national disaster and climate change risk assessments.

The implications of combined extremes events, with widening variability, concurrent with slowly emerging and ongoing impacts (such as rising sea-level and groundwater tables, greater frequency of heavy rainfall and longer and more intense droughts) can be examined in a dynamic systems framework using critical systems tools. This gives a richer assessment of the risks compared with

\footnotetext{
${ }^{3}$ National Policy Statement for Freshwater Management 2014 and as amended 2017
} 
traditional linear risk assessment methodologies as commonly practiced in New Zealand and elsewhere.

Common implications emerged that affect risk assessments and adaptation decisions taken by decision makers, for example;

- The strategic significance of the dependencies between three waters infrastructure, flood risk management and utilities planning;

- The need for integrated multi-hazard approaches to address the coincidence of many hazards in some locations;

- Limits to the current, largely reactive mode of responding to climate events as they happen, highlighting the need for anticipatory approaches;

- How collaborative models of public engagement hold promise for increased public understanding of how climate change impacts propagate and their significance for actions at difference levels of government;

- Highlighting the dependencies between land use and infrastructure planning when managing risk and vulnerability so cascading impacts of climate change can be addressed as the impacts worsen over time;

- For informing adaptations that are designed and deployed to 'fit the problem space' of changing risk and uncertainty and to help identify opportunities while managing risk.

By examining the dependencies and feedback loops between different systems of concern when stressed with changing climate impacts, we are able to 'stress-test' our risk assumptions. This can facilitate the design of adaptation responses that are flexible, yet robust under different future conditions, and thus avoid reaching thresholds that are beyond the ability of communities and physical systems to cope. Illustrating dependencies between urban systems, the financial sector and human wellbeing outcomes, is one demonstration of the value of considering cascading impacts. By understanding these linkages and prioritising the critical nodes, adaptation responses can be made more transparent. This suggests the role that decision tools (network and systems tools) can play in decision making in complex systems to facilitate a deeper understanding of how systems stressed by climate change might behave. By so doing, this can motivate a shift from considering single impacts that conceal the reality of climate change impacts, to a more nuanced approach based on the generative effect of compounding stresses. This can inform adaptive planning and the institutional and governance arrangements for delivering more effective adaptation alongside mitigation policy and practice.

\section{Author contributions}

JL, PB and NCH conceived and wrote the paper.

\section{Declaration of Competing Interest}

The authors declare that they have no known competing financial interests or personal relationships that could have appeared to influence the work reported in this paper.

\section{Acknowledgements}

The authors were funded by the New Zealand Deep South National Science Challenge Cascading climate change impacts in AotearoaNew Zealand project through the Ministry of Business, Innovation and Employment Contract \# CO1X1412. Thanks to Justin Connolly who produced the Fig. 2 systems map and methodology and Benjamin Nistor who assisted with the workshops. The authors thank all research participants for their contributions. Useful feedback was received from two anonymous reviewers.

\section{Appendix A. Supplementary data}

Supplementary data to this article can be found online at https://doi.org/10.1016/j.crm.2020.100234.

\section{References}

Ansell, T., Cayzer, S., 2018. Limits to growth redux: a system dynamics model for assessing energy and climate change constraints to global growth. Energy Policy 120, 514-525. https://doi.org/10.1016/j.enpol.2018.05.053.

Barnett, J., Graham, S., Mortreux, C., Fincher, R., Waters, E., Hurlimann, A., 2014. A local coastal adaptation pathway. Nat. Clim. Change 4, 1103-1108. https://doi. org/10.1038/nclimate2383.

Blenckner, T., Österblom, H., Larsson, P., Andersson, A., Elmgren, R., 2015. Baltic Sea ecosystem-based management under climate change: Synthesis and future challenges. Ambio 44, 507-515. https://doi.org/10.1007/s13280-015-0661-9.

Boin't, A., Hart, P., Stern, E., Sundelius, B., 2005. The Politics of Crisis Management: Public Leadership Under Pressure. Cambridge University Press, Cambridge Doi: $10.1017 /$ CBO9780511490880.

Bollinger, L.A., Dijkema, G.P.J., 2016. Evaluating infrastructure resilience to extreme weather - the case of the Dutch electricity transmission network 26.

Boston, J., Lawrence, J., 2018. Funding climate change adaptation: the case for a new policy framework. Policy Quarterly 14, 40-49.

Braun, V., Clarke, V., 2006. Using thematic analysis in psychology. Qualitative Res. Psychol. 3, 77-101. https://doi.org/10.1191/1478088706qp063oa.

Byers, E., Gidden, M., Leclère, D., Balkovic, J., Burek, P., Ebi, K., Greve, P., Grey, David, Havlik, P., Hillers, A., Johnson, N., Kahil, T., Krey, V., Langan, S., Nakicenovic, Nebjosa, Novak, R., Obersteiner, M., Pachauri, S., Palazzo, A., Parkinson, Simon, Rao, N., Rogelj, J., Satoh, Y., Wada, Y., Willaarts, B., Riahi, K., 2018. Global exposure and vulnerability to multi-sector development and climate change hotspots. Environ. Res. Lett. 13, 055012. https://doi.org/10.1088/1748-9326/aabf45.

Carey, M., Molden, O.C., Rasmussen, M.B., Jackson, M., Nolin, A.W., Mark, B.G., 2017. Impacts of glacier recession and declining meltwater on mountain societies. Ann. Am. Assoc. Geographers 107, 350-359. https://doi.org/10.1080/24694452.2016.1243039.

Carter, N., Viña, A., Hull, V., McConnell, W., Axinn, W., Ghimire, D., Liu, J., 2014. Coupled human and natural systems approach to wildlife research and conservation. 
Ecol. Soc. 19. https://doi.org/10.5751/ES-06881-190343.

Cash, D., Adger, W.N., Berkes, F., Garden, P., Lebel, L., Olsson, P., Pritchard, L., Young, O., 2006. Scale and cross-scale dynamics: governance and information in a multilevel world. Ecol. Soc. 11. https://doi.org/10.5751/ES-01759-110208.

CCATWG, 2017. Adapting to Climate Change in New Zealand: Stocktake Report from the Climate Change Adaptation Technical Working Group. Ministry for the Environment, Wellington.

CCATWG, 2018. Adapting to climate change in New Zealand: Recommendations from the Climate Change Adaptation Technical Working Group. Ministry for the Environment, Wellington.

Challinor, A.J., Adger, W.N., Benton, T.G., Conway, D., Joshi, M., Frame, D., 2018. Transmission of climate risks across sectors and borders. Phil. Trans. R. Soc. A 376, 20170301. https://doi.org/10.1098/rsta.2017.0301.

Cradock-Henry, Nicholas A., Connolly, Justin, Blackett, Paula, Lawrence, Judy, 2020. Elaborating a systems methodology for cascading climate change impacts and implications. MethodsX. https://doi.org/10.1016/j.mex.2020.100893. In this issue.

Connolly, J., Blackett, P., 2018. Systems maps outlining the cascading impacts of climate change. Report by Deliberate and NIWA for the Deep South National Science Challenge, Wellington, New Zealand. https://www.deepsouthchallenge.co.nz/sites/default/files/2019-02/The\%20Cascade\%20Effect\%20FINAL\%20REPORT\% 20Appendices\%20Low\%20Res.pdf.2018.

Cupples, J., Guyatt, V., Pearce, J., 2007. "Put on a Jacket, You Wuss": cultural identities, home heating, and air pollution in christchurch, New Zealand. Environ Plan A 39, 2883-2898. https://doi.org/10.1068/a3932.

da Silva, J., Kernaghan, S., Luque, A., 2012. A systems approach to meeting the challenges of urban climate change. Int. J. Urban Sustain. Devel. 4, 125-145. https:// doi.org/10.1080/19463138.2012.718279.

Fountain, A.G., Saba, G., Adams, B., Doran, P., Fraser, W., Gooseff, M., Obryk, M., Priscu, J.C., Stammerjohn, S., Virginia, R.A., 2016. The impact of a large-scale climate event on antarctic ecosystem processes. Bioscience 66, 848-863. https://doi.org/10.1093/biosci/biw110.

Galaz, V., Moberg, F., Olsson, E.-K., Paglia, E., Parker, C., 2011. Institutional and political leadership dimensions of cascading ecological crises. Public Administration 89, 361-380. https://doi.org/10.1111/j.1467-9299.2010.01883.x.

Gastelum, J.R., Krishnamurthy, G., Ochoa, N., Sibbett, S., Armstrong, M., Kalaria, P., 2018. The use of system dynamics model to enhance integrated resources planning implementation. Water Resour. Manage 32, 2247-2260. https://doi.org/10.1007/s11269-018-1926-4.

Gill, J.C., Malamud, B.D., 2016. Hazard interactions and interaction networks (cascades) within multi-hazard methodologies. Earth Syst. Dyn. 7, 659-679. https://doi. org/10.5194/esd-7-659-2016.

Givens, J.E., Padowski, J., Guzman, C.D., Malek, K., Witinok-Huber, R., Cosens, B., Briscoe, M., Boll, J., Adam, J., 2018. Incorporating social system dynamics in the columbia river basin: food-energy-water resilience and sustainability modeling in the Yakima River Basin. Front. Environ. Sci. 6. https://doi.org/10.3389/fenvs. 2018.00104 .

Guma, I.P., Rwashana, A.S., Oyo, B., 2018. Food security policy analysis using system dynamics: the case of uganda. IJITSA 11, 72-90. https://doi.org/10.4018/ IJITSA. 2018010104.

Hilly, G., Vojinovic, Z., Weesakul, S., Sanchez, A., Hoang, D.N., Djordjevic, S., Chen, A.S., Evans, B., 2018. Methodological framework for analysing cascading effects from flood events: the case of Sukhumvit Area, Bangkok, Thailand. Water 10 (81). https://doi.org/10.3390/w10010081.

Hounjet, M., Kieftenburg, A., Altamirano, A., 2016. Learning from flood events on critical infrastructure: relations and consequences for life and environment (CIrcle). In: Coastal Management, Conference Proceedings. ICE Publishing, pp. 407-413. https://doi.org/10.1680/cm.61149.407.

Hu, X., Hall, J.W., Shi, P., Lim, W.H., 2016. The spatial exposure of the Chinese infrastructure system to flooding and drought hazards. Nat. Hazards 80, 1083-1118. https://doi.org/10.1007/s11069-015-2012-3.

IPCC (Ed.), 2007. Climate Change 2007: Synthesis Report. Contribution of Working Groups I, II and III to the Fourth Assessment Report. Intergovernmental Panel on Climate Change, Geneva, Switzerland.

Johnson, C.R., Banks, S.C., Barrett, N.S., Cazassus, F., Dunstan, P.K., Edgar, G.J., Frusher, S.D., Gardner, C., Haddon, M., Helidoniotis, F., Hill, K.L., Holbrook, N.J., Hosie, G.W., Last, P.R., Ling, S.D., Melbourne-Thomas, J., Miller, K., Pecl, G.T., Richardson, A.J., Ridgway, K.R., Rintoul, S.R., Ritz, D.A., Ross, D.J., Sanderson, J.C., Shepherd, S.A., Slotwinski, A., Swadling, K.M., Taw, N., 2011. Climate change cascades: Shifts in oceanography, species' ranges and subtidal marine community dynamics in eastern Tasmania. J. Exp. Mar. Biol. Ecol., Global Change in Marine Ecosystems 400, 17-32. https://doi.org/10.1016/j.jembe.2011.02. 032.

Kinzig, A., Ryan, P., Etienne, M., Allison, H., Elmqvist, T., Walker, B., 2006. Resilience and regime shifts: assessing cascading effects. Ecol. Soc. 11.

Koks, E., 2018. Moving flood risk modelling forwards. Nat. Clim. Change 8, 561-562. https://doi.org/10.1038/s41558-018-0185-y.

Laing, D., 2018. Ability to stop or limit the provision of services infrastructure and potential liability consequences. Legal advice prepared for Local Government New Zealand. Wellington: Simpson Grierson Barristers and Solicitors. Retrieved from http://www.lgnz.co.nz/assets/Uploads/Legal-opinion-2-Ability-to-stop-or-limitthe-provision-of-services-infrastructure-and-potential-liability-consequences2.pdf.

Latham, A.D.M., Latham, M.C., Cieraad, E., Tompkins, D.M., Warburton, B., 2015. Climate change turns up the heat on vertebrate pest control. Biol Invasions 17, 2821-2829. https://doi.org/10.1007/s10530-015-0931-2.

Lawrence, J., 2016. Implicatons of climate change for New Zealand's natural hazards risk management. Policy Quarterly 12, 30-39.

Lawrence, J., Bell, R., Blackett, P., Stephens, S., Allan, S., 2018. National guidance for adapting to coastal hazards and sea-level rise: anticipating change, when and how to change pathway. Environ. Sci. Policy 82, 100-107. https://doi.org/10.1016/j.envsci.2018.01.012.

Lawrence, J., Blackett, P., Cradock-Henry, N. A., Flood, S., Greenaway, A., Dunningham, A., 2016. Synthesis Report RA4: Enhancing capacity and increasing coordination to support decision making. Climate Change Impacts and Implications (CCII) for New Zealand to 2100. MBIE contract C01X1225.

Lawrence, J., Blackett, P., Cradock-Henry, N.A., Nistor, B., 2019. Climate Change: The Cascade Effect. Deep South National Science Challenge, Wellington.

Local Government New Zealand, 2015. Local government funding review: A discussion document. LGNZ, Wellington.

Local Government New Zealand, 2019. Vulnerable: the quantum of local government infrastructure exposed to sea-level rise. LGNZ, Wellington.

Ludy, J., Kondolf, G.M., 2012. Flood risk perception in lands "protected" by 100-year levees. Nat Hazards 61, 829-842. https://doi.org/10.1007/s11069-011-0072-6.

Niiranen, S., Yletyinen, J., Tomczak, M.T., Blenckner, T., Hjerne, O., Mackenzie, B.R., Müller-Karulis, B., Neumann, T., Meier, H.E.M., 2013. Combined effects of global climate change and regional ecosystem drivers on an exploited marine food web. Glob. Chang. Biol. 19, 3327-3342. https://doi.org/10.1111/gcb.12309.

Ostrom, E., 2007. A diagnostic approach for going beyond panaceas. PNAS 104, 15181-15187. https://doi.org/10.1073/pnas.0702288104.

PCE, 2015. Preparing New Zealand for rising seas: Certainty and uncertainty. (Wellington: Parliamentary Commissioner for the Environment).

Pescaroli, G., Alexander, D., 2016. Critical infrastructure, panarchies and the vulnerability paths of cascading disasters. Nat. Hazards 82, 175-192. https://doi.org/10. 1007/s11069-016-2186-3.

Pescaroli, G., Nones, M., Galbusera, L., Alexander, D., 2018. Understanding and mitigating cascading crises in the global interconnected system. Int. J. Disaster Risk Reduct. 30 (B), 159-163. https://doi.org/10.1016/j.ijdrr.2018.07.004.

Pescaroli, G., Alexander, D., 2018. Understanding compound, interconnected, interacting, and cascading risks: a holistic framework. Risk Anal. 38 (11), $2245-2257$. https://doi.org/10.1111/risa.13128.

Reyer, C., Bachinger, J., Bloch, R., Hattermann, F.F., Ibisch, P.L., Kreft, S., Lasch, P., Lucht, W., Nowicki, C., Spathelf, P., Stock, M., Welp, M., 2012. Climate change adaptation and sustainable regional development: a case study for the Federal State of Brandenburg, Germany. Reg. Environ. Change 12, 523-542. https://doi. org/10.1007/s10113-011-0269-y.

Rocha, J.C., Peterson, G., Bodin, Ö., Levin, S., 2018. Cascading regime shifts within and across scales. Science 362, 1379-1383. https://doi.org/10.1126/science. aat7850.

Shimizu, M., Clark, A.L., 2015. Interconnected risks, cascading disasters and disaster management policy: a gap analysis. Planet@Risk 3.

Smith, D., Elliott, D. (Eds.), 2006. Key readings in crisis management: systems and structures for prevention and recovery. Routledge, London; New York.

Sterman, J.D., 2000. Business Dynamics: Systems Thinking and Modelling for a Complex World. McGraw-Hill, New York, NY.

Storey, Belinda, Noy, Ilan, 2017. Insuring property under climate change. Policy Quarterly 13 (4), 68-74. https://doi.org/10.26686/pq.v13i4.4603. 
Turner II, B., Esler, K.J., Bridgewater, P., Tewksbury, J., Sitas, N., Abrahams, B., Chapin III, F.S., Chowdhury, R.R., Christie, P., Diaz, S., Firth, P., Knapp, C.N., Kramer, J., Leemans, R., Palmer, M., Pietri, D., Pittman, J., Sarukhán, J., Shackleton, R., Seidler, R., van Wilgen, B., Mooney, H., 2016. Socio-Environmental Systems (SES) Research: what have we learned and how can we use this information in future research programs. Curr. Opinion Environ. Sustain., Sustain. Sci. 19, 160-168. https://doi.org/10.1016/j.cosust.2016.04.001.

Tyler, S., Moench, M., 2012. A framework for urban climate resilience. Clim. Devel. 4, 311-326. https://doi.org/10.1080/17565529.2012.745389.

Walker, B., Holling, C.S., Carpenter, S., Kinzig, A., 2004. Resilience, adaptability and transformability in social-ecological systems. Ecol. Soc. 9.

Walker, B.H., Abel, N., Anderies, J.M., Ryan, P., et al., 2009. Resilience, adaptability, and transformability in the Goulburn-Broken Catchment, Australia. Ecol. Soc. $14,12$.

Weisz, C., 2018. Resilient design: 'systems thinking' as a response to climate change. Arch. Des. 88, 24-31. https://doi.org/10.1002/ad.2255.

Wilbanks, T.J., Kates, R.W., 2010. Beyond adapting to climate change: embedding adaptation in responses to multiple threats and stresses. Ann. Assoc. Am. Geogr. 100, 719-728. https://doi.org/10.1080/00045608.2010.500200.

Williams, A., Kennedy, S., Philipp, F., Whiteman, G., 2017. Systems thinking: a review of sustainability management research. J. Cleaner Prod. 148, 866-881. https:// doi.org/10.1016/j.jclepro.2017.02.002.

Willner, S.N., Otto, C., Levermann, A., 2018. Global economic response to river floods. Nature Clim Change 8, 594-598. https://doi.org/10.1038/s41558-018-0173-2.

Winz, I., Brierley, G., Trowsdale, S., 2009. The use of system dynamics simulation in water resources management. Water Resour. Manage 23, 1301-1323. https://doi. org/10.1007/s11269-008-9328-7.

World Economic Forum, 2018. The Global Risks Report 2018 (No. (13th ed.)). World Economic Forum, Geneva, Switzerland.

Zevenbergen, C., Fu, D., Pathirana, A., 2018. Transitioning to sponge cities: challenges and Ippoertunities to address urban water problems in China. Water 201810 (9), 1230. https://doi.org/10.3390/w10091230. 